\title{
Meios de comunicação, alienação e extensão: a inocência no uso dos novos meios de comunicação
}

\author{
Media, alienation and extension: innocence in the use of new media \\ Medios, alienación y extensión: la inocencia en el uso de los nuevos \\ médios
}

Patricio DUGNANI ${ }^{1}$

\begin{abstract}
Resumo
Paradoxalmente, os meios são vistos como elementos que geram, tanto emancipação, como alienação. A crítica à alienação, é comumente observada no discurso da Escola de Frankfurt, enquanto a visão de emancipação, na Teoria dos Meios. Analisando essa questão de maneira dialética, pretende-se confrontar a visão funcionalista da Teoria dos Meios de Mcluhan, com a visão crítica da Escola de Frankfurt de Adorno e Horkheimer, para buscar uma síntese que demonstre como validas as duas ideias, e que os meios produzem tanto alienação, como emancipação. Para desenvolver essa questão, será observado como no início de qualquer revolução dos meios, a inocência dos usuários costuma facilitar o surgimento de figuras políticas com discursos fundamentalistas: foi assim com os meios de comunicação de massa e o Nazismo, tem sido assim com os meios digitais.
\end{abstract}

Palavras-chave: Meios de Comunicação; Alienação; Extensão; Fundamentalismos.

\begin{abstract}
Paradoxically, the means are seen as elements that generate both emancipation and alienation. The critique of alienation is commonly observed in the Frankfurt School discourse, while the vision of emancipation is in the Theory of Means. Analyzing this issue dialectically, we intend to confront the functionalist view of Mcluhan's Theory of Means, with the critical view of Adorno and Horkheimer's Frankfurt School, in order to seek a synthesis that demonstrates how the two ideas validate, and that the means

\footnotetext{
${ }^{1}$ Doutor em Comunicação e Semiótica PUC/SP, Mestre em Comunicação e Semiótica PUC/SP e Bacharel em Artes Plásticas pela Unesp - Professor nas áreas de Comunicação e Artes da Universidade Presbiteriana Mackenzie. Professor de Artes do Colégio Giordano Bruno. Pesquisador do Grupo de pesquisa Observatório da Imagem e pesquisador no grupo de pesquisa (CNPQ) Linguagem, sociedade e identidade: estudos sobre a mídia, da Universidade Presbiteriana Mackenzie - E-mail: patricio.dugnani@gmail.com - ORCID: 0000-0001-7877-4514.
} 
they produce both alienation and emancipation. To develop this question, it will be observed how at the beginning of any media revolution, the innocence of users usually facilitates the emergence of political figures with fundamentalist discourses: it was like that with the mass media and Nazism, it has been like that with the media digital.

Keywords: Media; Alienation; Extension, Fundamentalisms.

\section{Resumen}

Paradójicamente, los medios se ven como elementos que generan tanto la emancipación como la alienación. La crítica de la alienación se observa comúnmente en el discurso de la Escuela de Frankfurt, mientras que la visión de la emancipación está en la Teoría de los Medios. Analizando dialécticamente este tema, pretendemos confrontar la visión funcionalista de la Teoría de los medios de Mcluhan, con la visión crítica de la Escuela de Frankfurt de Adorno y Horkheimer, para buscar una síntesis que demuestre cómo las dos ideas se validan y que los medios que producen ambas alienación y emancipación. Para desarrollar esta pregunta, se observará cómo al inicio de cualquier revolución mediática, la inocencia de los usuarios suele facilitar el surgimiento de figuras políticas con discursos fundamentalistas: así fue con los medios de comunicación y el nazismo, ha sido así con los medios digitales.

Palabras clave: Medios; Alienación; Extensión; Fundamentalismos.

\section{Introdução}

"Hitler era admirado não a despeito de seus comportamentos grotescos ordinários, mas devido a eles".

Theodor Adorno

"Alguns idiotas até hoje ficam em casa".

Jair Bolsonaro

Cada época inventa seu projeto de idiotas. Numa pintura de Peter Brueguel, de 1559, é possível verificar uma alegoria que representa diversos provérbios da língua holandesa. Nessa peça, Brueguel parece não apenas querer registrar historicamente os provérbios, mas sim fazer uma crítica à condição confusa do ser humano. O quadro também foi denominado originalmente como $O$ manto azul, ou $O$ mundo confuso, o que reforçaria o posicionamento crítico do pintor quanto a sua época. Brueguel, através 
dos provérbios pretende criticar a tolice humana, que pela quantidade de figuras que compõem a pintura, não devem ser pouca (MIRANDA, 2017).

No momento contemporâneo, hipermoderno, no Brasil, pelo menos de acordo com o representante da república, o presidente Jair Bolsonaro, os idiotas são aqueles que ainda buscam se preservar de uma das piores pandemias dos últimos anos, a qual assola a população mundial (CARVALHO, 2021). Os idiotas são aqueles que respeitam as determinações de órgãos mundiais especializados na questão da saúde, como a Organização Mundial de Saúde, para evitar uma proliferação e a contaminação pelo vírus da Covid-19. Os idiotas são aqueles que não querem entrar para as estatísticas de morte, nem querem contaminar seus familiares, ou amigos. Os idiotas são aqueles que respeitam as indicações de evitar as aglomerações e utilizar a máscara para não ampliar a quantidade de mortos, que só no Brasil já ultrapassaram meio milhão de pessoas.

Tomando essa reflexão como início pretende-se verificar não a criação dos modelos de idiotas na história, mas como a inocência no uso dos meios de comunicação pode servir de suporte para criação de discursos alienados e figuras com discursos fundamentalistas que são capazes de levar milhares à morte: como Hitler.

Claro que não se pretende afirmar comprovadamente que a relação entre a introdução de novos meios de comunicação sempre esteja relacionada ao surgimento de figuras políticas com discursos mais radicais e fundamentalistas, mas sim, observar e indicar como esse fenômeno parece se repetir nas duas últimas revoluções tecnológicas dos meios de comunicação de massa no século XX e dos meios digitais no final do século XX e início do XXI.

A propósito, a frase da epígrafe desse artigo, que tão bem reflete esse modelo de político que tem se destacado nesses momentos: "Hitler era admirado, não a despeito de seus comportamentos grotescos ordinários, mas devido a eles" (ADORNO, 1994, p. 167, Apud. MURDOCH, 2018, p. 21), se refere a uma análise sobre a ascensão do Nazismo na Alemanha. O mais constrangedor dessa afirmação de Adorno, é que o representante político que ele cita, ainda parece muito com os atuais, justamente no momento da ascensão do uso dos meios digitais.

Sendo assim, este artigo surgiu para dar continuidade a uma pesquisa maior, que tem sido desenvolvida em paralelo, que busca entender a relação entre a Hipermodernidade, meios de comunicação, e sociedade. Esse debate busca compreender a relação entre a transformação da sociedade na era dos meios digitais, 
da internet e das redes sociais, verificando o quanto o uso desses meios de comunicação alteram o comportamento e as consciências do sujeito hipermoderno.

Metodologicamente, esse debate se baseia na visão da Teoria dos Meios de Marshall Mcluhan (2016), que entende os meios de comunicação não apenas como suportes de transmissão, mas como agentes transformadores da sociedade; e, dialeticamente, essa visão será contraposta com as conclusões da Escola de Frankfurt, nas palavras de Theodor Adorno e Max Horheimer (2000), que observam a Indústria Cultural, e a fabricação de informação seriada e uniformizada (massificada), que é produzida pelos meios de comunicação de massa, como produtores de alienação. Ou seja, será importante para o diálogo desse artigo, as visões contraditórias da Teoria Crítica da Escola de Frankfurt e da Teoria dos Meios, pois, enquanto uma observa os meios de comunicação como produtores de alienação, a outra vê como emancipação, extensão. Essa contradição é motivadora, pois será possível observar o quanto os efeitos do uso dos meios de comunicação são paradoxais.

Além disso, para poder identificar como se caracteriza o momento contemporâneo, a análise de Hartmut Rosa (2019), dos efeitos que a aceleração, a qual tem produzido mudanças na sociedade (denominada pelo autor) hipermoderna. Dentro dessa visão, Rosa (2019) observa atentamente a aceleração dos processos que constituíram a Modernidade. Por causa dessa posição, é que esse artigo abdica do termo mais comum, usado para definir a contemporaneidade: Pós-modernidade. Isso, pois se entende que a contemporaneidade não apresenta muita originalidade em relação à Modernidade, apenas se verifica uma aceleração nos seus processos: tanto na troca de informações, quanto nas transformações sociais; tanto na valorização do ato de tornar-se visível (aparecer), quanto na busca constante em saciar os desejos (hedonismo); tanto na sensação de incerteza sobre o futuro, quanto pela nostalgia por um passado imaginado como perfeito, que sequer se viveu: a retrotopia descrita por Zygmunt Bauman (2017).

A visão metodológica que orienta esse artigo, está também vinculada a uma pesquisa mais ampla do autor, que busca entender a relação entre o uso dos meios de comunicação e a constituição dos discursos que caracterizam a Hipermodernidade. Essa pesquisa mais ampla está apoia-se na visão de Michel Foucault em constituir um método arqueológico de análise: sua Arqueologia do Saber. Demonstra-se, dessa forma, o interesse em revelar os paradigmas e assinaturas dos discursos que compõem o pensamento de uma determinada sociedade, nesse caso, a Hipermodernidade. Essa 
estratégia pretende compreender o pensamento de uma época, de acordo com o método da Arqueologia do Saber de Foucault (2012 e 1990), e pela atualização à essa visão metodológica, descrita por Giorgio Agamben, em seu livro Signatura Rerun (2019).

\section{Meios de comunicação e o estereótipo da inocência em dois filmes}

Talvez uma das cenas do cinema que melhor representam a inocência dos usuários ao utilizar um meio de comunicação, quando está começando a ser apresentado para a sociedade, é a personagem Miss Bessie Polk, interpretada por Ida Moore. O filme em questão é Rock-a-bye baby, traduzido para o Brasil como: Bancando a ama seca. O filme foi lançado em 1958, dirigido por Frank Tashlin e estrelado pelo ator e diretor Jerry Lewis.

Na cena, Jerry Lewis, interpretando Clayton Poole, vai se despedir de Miss Bessie Polk. No entanto, ele chega na hora do intervalo do programa de TV, momento em que Miss Polk está concentrada nos comerciais. Na cena, em apenas uma sequência, três produtos são apresentados. E enquanto o locutor faz as demonstrações dos produtos, ela os consome, sendo servida pelo personagem de Jerry Lewis, tendo como música de fundo, os jingles dos comerciais: 1- Café Com Antigo Sabor Verdadeiro: só café; 2- Cigarro Soberbo: filtro nas duas pontas; 3-Arrotex: para dor no estômago.

No final do horário comercial, quando volta a transmissão do programa, Miss Bessie sentencia: "Sabe, eu acredito muito na lealdade dos anunciantes. Esse é um erro do mundo de hoje, não há muita lealdade”. Essa personagem, sem pestanejar, fez uso de um remédio, fumou um cigarro e tomou café, apenas porque o locutor ofereceu. Essa ação, mesmo sendo caricata e dramática, demonstra essa ideia da inocência do usuário de um meio recentemente introduzido na sociedade, nesse caso, a TV, meio elétrico e meio de comunicação de massa.

Um exemplo mais recente é possível verificar no filme $O$ círculo (2017). Esse filme foi dirigido por James Ponsoldt, e estrelado por Emma Watson, Tom Hanks, Karen Gillian e John Boyega. Nele, Emma Watson, interpretando Mae Holland, é contratada pela empresa The Circle (O Círculo) e acaba convencida que não deve existir restrição quanto ao acesso à informação. Além disso, de que todas as informações devem ser disponibilizadas na rede. A partir dessa decisão, ela passa a deixar sua vida 
toda exposta através de uma câmera, e convive com um dilema existencial: até onde vai o limite entre o público e o privado?

Nos dois exemplos, percebe-se um alto grau de idealismo e de inocência das duas personagens, em relação ao uso de um novo meio introduzido na sociedade: o primeiro são os meios de comunicação de massa, enquanto o segundo são os meios de comunicação digitais, representados, principalmente, pelas redes sociais e a internet. Tanto Miss Bessie, como Mae Holand são estereótipos que, embora ficcionais, são capazes de representar a relação inocente que os receptores apresentam, quando na época da introdução de novos meios de comunicação na sociedade.

O início da introdução dos meios de comunicação de massa, no século XX, é marcado pela inocência do uso desses novos meios, característica constante das últimas grandes revoluções tecnológicas dos meios de comunicação, os quais foram suportes que ajudaram a construir, a partir do ideário humano (fato que não se pode deixar de citar) figuras com posições políticas mais radicais no ambiente político, sejam elas de direita, esquerda, ou de outras posições ideológicas.

Os meios de comunicação de massa, por exemplo, foram ferramentas que auxiliaram a ascensão de uma figura como Hitler e disseminar o Nazismo. Isso é verdadeiro, mas, infelizmente, não pertence ao passado. Ao que parece esse fenômeno está se repetindo no século XXI, pois com o desenvolvimento dos meios digitais, e, principalmente das redes sociais - além da falta de malicia no uso desses meios, e seu uso ideológico - fez surgir, ou diria, ressurgir no cenário político contemporâneo, figuras com discursos fundamentalistas.

Mais a frente, pretende-se confrontar pela Teoria dos Meios de Mcluhan (2016), e pela Teoria Crítica da Escola de Frankfurt, o início do desenvolvimento dos meios de comunicação de massa e dos digitais, com a inocência do seu uso, e o surgimento de figuras políticas que parecem resgatadas de um passado não tão distante.

\section{Os meios de comunicação, extensão, alienação e estereotipização da política}

Quando os meios de comunicação de massa começaram a serem introduzidos na sociedade, paralelamente, os estudos de comunicação se multiplicaram, principalmente da linha funcionalista, representada por Harold Lasswell e a Mass communication research (MATTELART, 1999). Nesse momento, o discurso de Lasswell, influenciado pelos acontecimentos da II Guerra Mundial, e o conflito 
ideológico que se punha entre o Capitalismo, o Socialismo e o Nazismo, era o de proteção ao modo de vida, à cultura, no caso, a norte-americana. Percebe-se isso, tanto na primeira teoria criada para os meios de comunicação de massa, da agulha hipodérmica, quanto nas funções sociais da comunicação desenvolvidas pelo teórico. A primeira dizia que os indivíduos mais suscetíveis à influência dos meios de comunicação de massa, eram aqueles que tinham menor vínculo social (MATTELART, 1999), enquanto as três funções sociais da comunicação ensinavam como proteger sua população dessa influência: através da vigilância dos conteúdos transmitidos pelos meios, do fortalecimento das relações sociais, e a manutenção das heranças sociais. Com isso, de certa forma, Lasswell lançava algumas das bases da visão funcionalista dos estudos de comunicação, mas também sentenciava os meios de comunicação de massa para uma missão paradoxal: informar e proteger.

Contudo, como informar e proteger sem influenciar politicamente, e numa visão mais frankfurtiana, sem alienar o sujeito?

Com esse dilema, a linha de estudos de comunicação norte-americana, acaba por revelar um problema que está sempre assombrando os processos de comunicação, e, de maneira especial, os meios de comunicação de massa: como informar sem alienar?

Enfim, ao procurar proteger seu modo de vida, sua cultura, como se ela fosse hermética, pura e concebida sem misturas de outras ideias de comunidades diferentes? O uso dos meios de comunicação acaba por criar uma falsa bolha sobre as diferentes culturas. Afinal de contas, não existe uma cultura pura, mas sim formada historicamente pela mistura de tantas outras. Esse mito da cultura pura, já produziu violência demais na história, sem que seja abandonado, mas sim, que permaneça, muitas vezes, oculto no discurso humano.

Com isso, essa busca em proteger a cultura de um grupo humano, pode gerar, ao invés de informação, alienação, pois acaba por ocultar a contradição, fator indispensável para o desenvolvimento de uma postura crítica. Quando a disseminação de informação é limitada por questões ideológicas, faz surgir a alienação, concordando com a visão dialética da Escola de Frankfurt (ADORNO e HORKHEIMER, 2019).

Essa contradição entre informação e alienação através dos meios de comunicação, é uma motivação para os debates entre a Teoria dos Meios de Mcluhan, (2016) e a visão de Adorno e Horkheimer (2019 e 2000) da Escola de Frankfurt. Por causa disso, é nessa zona contraditória do embate dessas duas visões, é que, para esse 
artigo, nasce um debate pródigo para compreender de maneira mais ampla, o uso dos meios de comunicação.

De maneira positiva, Mcluhan (2016) vê os meios de comunicação como extensões da percepção, dos sentidos, e, mesmo, do sistema nervoso humano. Ou seja, os meios são capazes de ampliar a percepção humana, fazendo com que alcance lugares que antes não poderiam ser acessados apenas pelos sentidos naturais (visão, audição etc.). Como os meios estendem à percepção, também são capazes de fazer com que os seres humanos acessem mais informações, bem como tenham mais experiências num mesmo período. Com isso, e com o uso dos meios, principalmente os elétricos, na visão de Mcluhan (2016), o ser humano deverá, futuramente, constituir uma cultura comum, de coletividade, a qual ele denomina de Aldeia Global.

Tomando um parêntesis, essa visão utópica do autor, parece se distanciar, quando se observa a polarização, a desglobalização e a divisão dos grupos humanos que tem ocorrido desde o advento dos meios digitais, e que diversos autores têm criticado. Autores como Murdock (2018), e a visão da refeudalização, Baitello (2015) e a pulverização das comunidades formadas a partir dos meios de comunicação de massa, e Dugnani (2018) e a contradição entre meios globalizantes e políticas desglobalizantes, têm se debruçado sobre um paradoxo delicado que surge com o uso dos meios de comunicação a partir da utilização da eletricidade: o que deveria desenvolver uma sociedade global e coletiva, está, na verdade, produzindo fragmentação e ampliando o individualismo da população.

Já a Escola de Frankfurt pela visão de Adorno e Horkheimer (2019) de uma maneira crítica, observa o uso dos meios de comunicação, principalmente os de massa, como produtores de alienação, por se assimilarem, na sua produção de informação, à verdadeiras indústrias, indústria de manifestações culturais, por fim, Indústria Cultural. A alienação que se dá através dos meios de comunicação de massa ocorre por uniformização dos conteúdos, denominado massificação. Ou seja, como nos meios de comunicação de massa, a informação é vista como produto, como mercadoria, quais conteúdos devem ser transmitidos por esses meios acaba sendo determinado pelo mercado, e pela possibilidade de consumo. Dessa forma, como a decisão sobre quais informações devem ser transmitidas por esses meios, depende da audiência que elas dão, a divisão do espaço de divulgação de informação não é equilibrada, sendo que o maior espaço sempre é dado às informações que dão maior visibilidade. Com isso, a circulação de informação acaba se tornando limitada e repetitiva, pois os meios de 
comunicação, funcionando como verdadeiras fábricas de manifestações culturais e de conteúdos, produzem e reproduzem as informações de maneira seriada, criando com o tempo uma cultura determinada por um gosto médio, um gosto baseado na média estatística da massa, uma cultura de massa. Com essa massificação, ou seja, essa limitação do espaço de transmissão de conteúdos, e essa repetição das mesmas informações, o espaço crítico de contraposição de ideias acaba sendo limitado, o que produz um processo alienatório. Por isso, para Escola de Frankfurt, o espaço da comunicação em massa é produtor de alienação.

Observando essas duas visões, em um ponto, embora discordem quanto a positividade ou negatividade do uso dos meios de comunicação, a Teoria dos Meios e a Escola de Frankfurt revelam o duplo funcionamento que os meios elétricos (meios de comunicação de massa e meios digitais) têm apresentado: eles são extensões da percepção humana, mas promovem também alienação. Nem sempre informação e esclarecimento andam juntas, e é nesse hiato entre informação e alienação, somada à uma inocência inicial em relação aos novos meios de comunicação, é que acabam por fazer ressurgir os discursos de ódio, os fundamentalismos e, talvez um dos seus grandes produtos, figuras políticas com discursos fundamentalistas.

Essas figuras fundamentalistas, como apresentada por Adorno (Apud. MURDOCK, 2018) para caracterizar Hitler, acabam por se constituir e divulgar seus ideais como se suas verdades fossem absolutas e inquestionáveis. Essas aparentes verdades se constituem por uma naturalização da história, do social, das ideologias, como afirma Roland Barthes (1999), e são baseadas, não em fatos objetivos, mas em crenças, em opiniões pessoais. Por isso, o fenômeno da pós-verdade, tão discutida na Hipermodernidade, não pode ser considerado novo, como afirma Helder Prior:

Porém, a palavra "pós-verdade" pode ter entrado no léxico apenas recentemente, tendo inclusivamente sido considerada palavra do ano de 2016 para os Dicionários Oxford, mas não se deve esquecer que as últimas décadas também nos trouxeram alguns exemplos de notícias falsas ou de "factos alternativos" que se impuseram sobre a verdade. (PRIOR, 2019, p. 89).

Não é que a pós-verdade surgiu na Hipermodernidade, mas com a evolução tecnológica dos meios de comunicação digitais, a aceleração das trocas de informação (ROSA, 2019), esse fenômeno se multiplicou e ganhou destaque nos debates sociais, demonstrando seu poder em acontecimentos que causaram transformações mundiais, 
além do retorno de discursos mais radicais, nacionalistas, e ou fundamentalistas, como a eleição de Donald Trump e o Brexit (D’ANCONA, 2018 e CÁDIMA, 2018).

Hoje, as fake news são sobretudo um sintoma de um cerco progressivo - potencialmente fatal -, ao jornalismo e ao sistema democrático, cerco que tem vindo a retirar a essência e o escrutínio do "quarto poder" na sociedade contemporânea, deixando-a cada mais frágil. Os agentes e temas promotores das fake News estão, em geral, identificados. Encontramos desde casos em que emerge apenas a manipulação ou a mera falsidade sem grandes consequências, às estratégias interesseiras a qualquer preço; propaganda extremista, ou discurso do ódio. Outros casos, talvez os mais perigosos, vão desde o envolvimento na geopolítica internacional e na "ciberguerra" às motivações de forte enviesamento político com impacto em importantes eleições nacionais (Brexit e presidenciais dos EUA em 2016, presidenciais francesas em abril de 2017 e alemãs também em 2017, referendo na Catalunha em 2017, etc.), para só citar alguns dos casos mais recorrentes. (CÁDIMA, 2018, p. 22-23).

Esse fenômeno que se abateu nos meios de comunicação de massa, também contaminou os meios digitais. Ou seja, todos os meios elétricos demonstram que foram usados em sua origem como uma forma de produzir alienação, se aproveitando tanto da inocência dos receptores, quanto do potencial de influenciar as vontades, os gostos e as ideologias dos receptores em massa, criando um campo fértil para disseminação de figuras políticas que parecem ter saído de um passado recente, como aquelas que figuravam na ascensão da extrema direita, no início do século XX.

Se nos meios de comunicação de massa ocorreu uma massificação da informação, nos meios digitais, é possível dizer que houve uma internetilização (uma massificação nas informações na Internet), pois em ambos, a informação acaba por ser uniformizada. No primeiro a informação foi uniformizada para o gosto médio da massa, a partir da pesquisa de mercado e o fato de dar maior espaço para conteúdos que dessem mais audiência. No segundo a informação está sendo uniformizada pelas bolhas de interesse, fragmentadas e organizadas pelos algoritmos, que escolhem as informações que devem ser recebidas pelos receptores dos meios digitais.

Este tema do discurso aberto vs. "bolhas" veio afinal colocar em evidência algo que sempre se configurou como uma categoria sempre presente embora bem disfarçada. O facto de estarmos perante uma nova lógica pós-mediática não significa que essa "tematização" não estivesse desde há muito na agenda política e mediática. Na verdade, não há, por assim dizer, nada de substancialmente novo, a não ser o que tem a ver intrinsecamente com o digital e as suas dimensões computacionais e informacionais, com a IA, o machine learning, o uso de perfis de utilizadores e a velocidade e automatização da informação. 
Aqui, sim, há diferenças relativamente à velha experiência dos media tradicionais (CÁDIMÁ, 2018, p. 25).

Nesse processo de alienação, implementada nos meios de comunicação digitais, cria-se uma falsa impressão de que o receptor é potente e detentor do direito de escolher quais conteúdos quer acessar, quando, na verdade, acaba sendo influenciado e tendo seu acesso às informações limitadas pelos algoritmos. A aparente infinita quantidade de informações que os receptores dos meios digitais teriam a disposição, acabam sendo ocultadas por um universo limitado de conteúdos uniformizados e medidos por um termo: relevância.

A relevância seria a audiência disfarçada dos meios de comunicação de massa, mas que, no momento contemporâneo, as grandes instituições, principalmente as plataformas de redes sociais, utilizam para medir os gostos comuns da população. Nesse processo, os algoritmos são usados para monitorar e rastrear os acessos, e metrificar esses gostos (CÁDIMA, 2018), justamente para limitar a escolha do receptor. Nessa nova métrica oferecem sempre os produtos relacionados a esse gosto individualizado. As mesmas informações, tratadas como sempre: feito mercadorias.

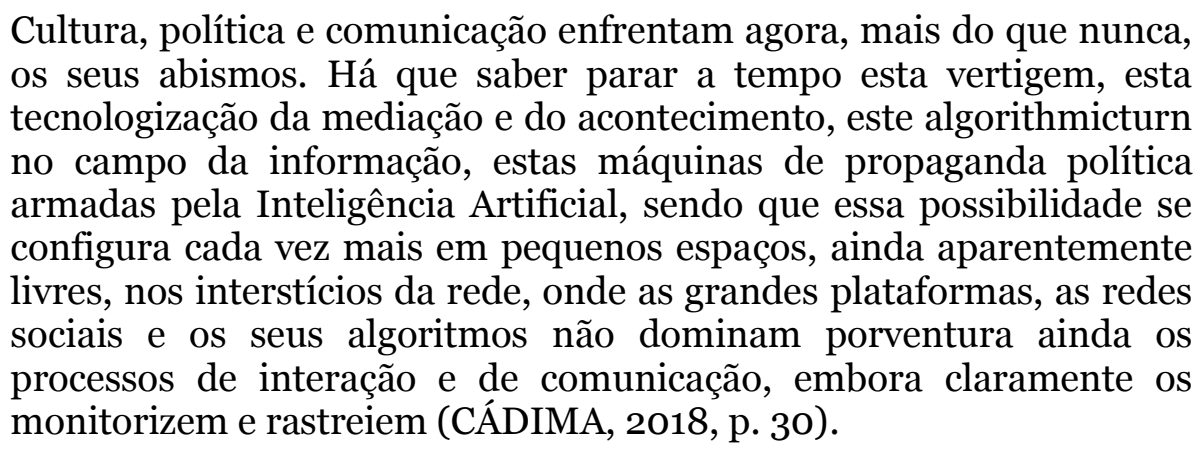

Um agravante dessa situação, que a inocência do receptor parece não perceber, é que as grandes plataformas de redes sociais têm como produto principal a informação, a qual é fornecida pelos seus usuários. E como Ana Regina Rego (2020) afirma, acaba sendo objetivo dessas empresas que os usuários fiquem o máximo de tempo possível, pois assim eles podem produzir mais informação, para ser comercializada por elas. Ou seja, de certa forma, toda informação produzida pelos usuários para as redes sociais são produtos comercializados por essas grandes plataformas. Assim, todo usuário das redes sociais, e da internet em geral, é um operário, ou melhor, um escravo não remunerado, que trabalha para essas empresas, sem ganhar um salário, mas apenas por vaidade e pela possibilidade de aparecer com 
seus perfis nas redes sociais, para quem sabe um dia, conseguir sobreviver, como um influenciador.

O objetivo das empresas além dos ganhos financeiros através das relações de poder no mercado midiático on-line e empresarial, é fazer com que continuemos a fornecer nosso tempo gratuitamente alimentando de informações de modo incessante as estruturas midiáticas que disponibilizam em "nosso favor". Quanto mais tempo ficamos on-line e quanto mais trabalhamos de graça, mais conteúdo produzimos e mais informações pessoais disponibilizamos e estas são armazenadas, analisadas e circulam e, principalmente, são negociadas (REGO, 2020, p. 88).

Essa inocência quanto ao uso dos novos meios de comunicação, pelo menos em relação aos meios elétricos (meios de comunicação de massa e meios digitais), a cada época se renova, mas parece que se repete em uma constante a disseminação de ideias mais radicais, fundamentalistas, e de verdades que se projetam como absolutas, mas que não passam de crenças, ou opiniões pessoais. Essa constante se denomina na Hipermodernidade como pós-verdade, mas já se caracteriza como uma dinâmica antiga, a qual acaba por multiplicar esses discursos, alimentar tendências fundamentalistas, como o negacionismo, e acabam por criar um espaço fértil para a proliferação das figuras com discursos fundamentalistas.

Se é possível vislumbrar figuras que parecem resgatadas de um passado recente na política contemporânea, as quais parecem resgatar discursos de extrema direita, como os utilizados por Hitler, também é possível observar que tanto no início do século XX, como agora, início do XXI, a disseminação desses discursos é mediada pela revolução dos meios de comunicação e a inocência dos que se utilizam desses meios. $\mathrm{O}$ discurso do nazismo foi disseminado pelo uso eficiente dos meios de comunicação de massa, apoiado pelas estratégias de Joseph Goebbels, seu ministro da comunicação, e pela inocência de uma população deslumbrada com o potencial e o alcance das informações. Na atualidade hipermoderna, é possível identificar o mesmo processo, mas agora mediado pelo uso dos meios de comunicação digitais, os quais possibilitaram o ressurgimento desses discursos, os quais geram visões fundamentalistas, e ajudam na proliferação de fake news, bem como da profusão de posições polarizadas.

\section{Considerações finais}


A inocência, muitas vezes, não pode ser considerada apenas uma virtude, mas uma ação que por vezes oculta, ou uma alienação, ou um mal. Esse mal, que Hannah Arendt (2004) descreve, quando observava no momento dos julgamentos de Nuremberg, não era radical, mas surgia protegido por um discurso de alienação e de obediência às leis. Ou seja, uma das defesas de Adolf Eichmann, ex-oficial nazista, julgado por ser responsável pelo transporte das vítimas do Holocausto durante a II Guerra Mundial, era que sua inocência estaria fundamentada no fato de apenas estar obedecendo ordens. Sendo assim, as relações éticas e morais que eram rompidas pelas ações nazistas, para Eichmann, eram justificadas, pela alienação do próprio sujeito, que naturalizava (BARTHES, 1999), transformava história em um fato natural.

A naturalização do mal, o torna cotidiano, não radical, o que, para Arendt (2004), constitui um problema muito mais profundo, pois esse mesmo mal, não se apresenta como perverso, mas como inocente, cotidiano e legalizado por qualquer discurso. Esse mal que nasce da alienação, da inocência é extremo, e pode, para Arendt (2004) atingir o mundo inteiro: "O maior mal não é radical, não possui raízes, e, por não ter raízes, não tem limitações, pode chegar a extremos impensáveis e dominar o mundo todo" (ARENDT, 2004, p.160). Essa citação de Arendt (2004), parece refletirse agora, quando observamos o ressurgimento de discursos de ódio, por trás de atitudes fundamentalistas e negacionistas, que inundam as redes sociais. A inocência encoberta pela alienação e a ignorância, perigosamente tem sido cada vez mais observado nos conteúdos dos meios de comunicação.

Com essa reflexão, a inocência do uso dos meios de comunicação, seja na época da introdução dos meios de comunicação de massa, seja na época dos meios digitais, tem se alicerçado nos discursos que povoam esses meios, além de serem disseminados através deles. Esses discursos, na hipermodernidade, estão promovendo as posições mais fundamentalistas e, consequentemente, alienação através da repetição das mesmas informações a determinados grupos, que ficam limitadas às bolhas de informação, produzidas pela utilização dos algoritmos. Dentro de suas bolhas, onde os discursos são retrovalidados por opiniões que não se contradizem dialeticamente, essas comunidades continuamente cultuam o mal descrito por Arendt (2004), apoiados em uma inocência legalizada, normatizada, naturalizada, de maneira alienada, sendo alimentada por fake news (boatos, notícias falsas), que criam uma verdade conveniente, e não objetiva, que atualmente denominamos como pós-verdade (PRIOR, 2019). 
Contudo, não se pode atribuir esse fenômeno exclusivamente ao momento contemporâneo da Hipermodernidade e do uso inocente dos meios digitais (PRIOR, 2019), mas é preciso perceber que esse fenômeno sempre esteve presente, inclusive na introdução dos meios de comunicação de massa no século XX. Por isso, esse artigo, como dito anteriormente, não pretende comprovar que a introdução de novos meios de comunicação sempre promove o surgimento de figuras fundamentalistas no ambiente político, mas sim, alertar que o uso inocente e descuidado dos meios de comunicação, pode gerar uma naturalização de posições mais radicais.

Não pretende comprovar, mas busca servir de alerta, para que os meios de comunicação não sejam suportes de discursos de ódio, por seu uso inocente, mas que sejam instrumentos de esclarecimento, para que possam, finalmente, quem sabe, cumprir a promessa libertadora do iluminismo, ao invés de serem, como sentenciam Adorno e Horkheimer (2019 e 2000), mais um instrumento de mistificação e alienação.

\section{Referências}

ADORNO, Theodor; HORKHEIMER, Max. Dialética do Esclarecimento. Rio de Janeiro: Zahar, 2019.

ADORNO, Theodor; HORKHEIMER, Max. Indústria Cultural: O Iluminismo como mistificação das Massas. In: LIMA, L. C. (org.). Teorias da Cultura de Massa. São Paulo: Paz \& Terra, 2000.

AGAMBEN, G. Signatura rerum. São Paulo: Boitempo, 2019.

ARENDT, Hannah. Algumas Questões de Filosofia Moral. In: Arendt, H.

Responsabilidade e julgamento. São Paulo: Companhia das Letras, 2004.

BAITELLO, Norval. (A massa sem corpo), (o corpo sem massa), (a massa sem massa), (o corpo sem corpo. As redes sociais como ambientes de ausência (e fundamentalismos). In: LOPES, M. I. V. de, e, KUNSCH, Margarida Maria Krohling (org.). Comunicação, cultura e mídias sociais. São Paulo: ECA-USP, 2015.

BARTHES, Roland. Mitologias. Rio de Janeiro: Bertrand. 1999.

BAUMAN, Zygmunt. Retrotopia. Rio de Janeiro: Zahar, 2017.

CÁDIMA, R. A rede na estratégia da aranha: "pós-verdade”, política e regressão.

Observatório. 2018. Disponível em:

http://obs.obercom.pt/index.php/obs/article/view/1294. 
CARVALHO, Daniel. Tem alguns idiotas que até hoje ficam em casa, diz Bolsonaro sobre isolamento na pandemia. Folha de São Paulo.17.mai.2021 às 10h51. Atualizado: 17.mai.2021 às 11h33. Disponível em: https://www1.folha.uol.com.br/poder/2021/05/temalguns-idiotas-que-ate-hoje-ficam-em-casa-diz-bolsonaro-sobre-isolamento-napandemia.shtml.

D'ANCONA, Matthew. Fake News: A nova guerra contra os fatos em tempos de fake News. São Paulo: Faro Editorial, 2018.

DUGNANI, Patricio. Globalização e desglobalização: outro dilema da Pós-Modernidade. Revista Famecos, Porto Alegre, v. 25, n. 2, p. 1-14, maio, junho, julho e agosto de 2018: ID27918. DOI: http://dx.doi.org/10.15448/1980-3729.2018.2.27918.

FOUCAULT, Michel. As Palavras e as Coisas. São Paulo: Martins Fontes, 1990.

FOUCAULT, Michel. A Arqueologia do Saber. Rio de Janeiro: Forense Universitária, 2012.

GAZETA. 434 mil mortes "Alguns idiotas até hoje ficam em casa", diz Bolsonaro sobre isolamento. (17/05/2021). Disponível em:

https://www.agazeta.com.br/brasil/alguns-idiotas-ate-hoje-ficam-em-casa-diz-bolsonarosobre-isolamento-0521.

MATTELART, Armand; MATTELART, Michele. História das Teorias da Comunicação. São Paulo: Loyola, 1999.

MCLUHAN, Marshall. Os Meios de Comunicação como Extensões do Homem. Cultrix: São Paulo, 2016.

MIRANDA, Carlos Alberto Cunha. A arte de curar nos tempos da colônia: limites e espaços da cura. Recife: Ed. Universitária da UFPE, 2017.

MURDOCK, Graham. Refeudalização revisitada: a destruição da democracia deliberativa. Matrizes, São Paulo, V.12 - No 2 maio/ago, p. 13-31. 2018. Disponível em: http://www.revistas.usp.br/matrizes/issue/view/10795. Acesso em: 14/o9/2018.

PRIOR, Hélder. Mentira e política na era da pós-verdade: fakenews, desinformação e factos alternativos. (2019). In: P. Lopes \& B. Reis (eds.), Comunicação Digital: media, práticas e consumos (pp. 75-97). Lisboa: NIP-C@M \& UAL. Disponível em http://hdl.handle.net/11144/3976. https://doi. org/10.26619/978-989-8191-87-8.4. Acesso em janeiro de 2021.

REGO, Ana Regina. Vigilância, controle e atenção: a desinformação como estratégia.

Organicom. Ano 17, n. 34, set./dez. 2020. Disponível em:

https://www.researchgate.net/publication/349987911_Vigilancia_controle_e_atencao_a_d esinformacao_como_estrategia.

ROSA. Hartmut. Aceleração A transformação das estruturas temporais na Modernidade. São Paulo: Unesp, 2019. 